\title{
The roles of wing color pattern and geography in the evolution of Neotropical Preponini butterflies
}

\author{
Elena Ortiz-Acevedo ${ }^{1}$, Juan Gomez ${ }^{1}$, Keith Wilmott ${ }^{2}$, Marianne Espeland ${ }^{3}$, and \\ Emmanuel Toussaint ${ }^{4}$ \\ ${ }^{1}$ Universidad del Norte \\ ${ }^{2}$ University of Florida \\ ${ }^{3}$ Zoological Research Museum Alexander Koenig \\ ${ }^{4}$ Natural History Museum of Geneva
}

June 8, 2020

\begin{abstract}
Diversification rates and evolutionary trajectories are known to be influenced by phenotypic traits and the geographic history of the landscapes that organisms inhabit. One of the most conspicuous traits in butterflies is their wing color pattern, which has been shown to be important in speciation. The evolution of many taxa in the Neotropics has also been influenced by the closure of the Panama Isthmus and the dynamic uplift of the Andes. Using a dated, species-level molecular phylogenetic hypothesis for Preponini, a colorful Neotropical butterfly tribe, we evaluated if diversification rates were constant or varied through time, and if they were dependent on color patterns or biogeographic events. We also estimated the rate of forewing color evolution and ancestral geographic ranges. We found that Preponini originated approximately 28 million years ago and that diversification has increased through time dependent on Andean uplift. Even though some clades show evolutionarily rapid transitions in coloration, these traits seem decoupled from diversification regimes. Preponini apparently originated within South America and range evolution has since been dynamic, congruent with Andean geologic activity, closure of the Panama Isthmus and Miocene climate variability. The potential involvement in mimicry rings with other butterfly groups might explain rapid changes in dorsal color patterns in this tribe.
\end{abstract}

\section{Introduction}

Some phenotypic traits may serve as key innovations that facilitate rapid diversification, influencing the evolutionary origins and trajectories of lineages (Mayhew, 2007; Nicholson et al., 2014; Schluter, 2000). One of the most visually spectacular phenotypic traits are the bright color patterns in several insect groups, and a number of studies have focused on the evolution of these color patterns and the possible roles they might have played in the evolution of insects (Berthier, 2005; Jiggins et al., 2001; Kemp, 2007; Mallet \& Gilbert, 1995). In butterflies, for example, wing color pattern is a trait that has attracted the attention of naturalists since Darwin's and Wallace's observations in the $19^{\text {th }}$ century (Darwin, 1880, 1874; Wallace, 1889, 1877), and it has proven to be key in intra- and interspecific interactions and speciation processes in butterflies (e.g. Lycaenidae; Fordyce et al., 2002; Heliconius ; Jiggins et al., 2006; Heliconius ; Mavarez et al., 2006).

As an alternative to trait-dependent diversification, geographic events can also promote diversification and range evolution. Understanding the biogeography of diverse Neotropical clades is therefore also key to obtain insights about the origins of extant biodiversity. There have been many changes in Neotropical landscape's configuration that have influenced the distribution and evolutionary trajectories of organisms (Antonelli et al., 2018; Hoorn et al., 2010). For example, the Andean uplift that started around 30 Ma has been one of 
the key drivers of speciation and range evolution in the Neotropical biota (Smith et al., 2014). This uplift created major rearrangements of internal wetlands that provided novel habitats and were important barriers to dispersal (Chazot et al., 2019; Rahbek et al., 2019). The formation of the Panama Isthmus was another major biogeographic event that promoted the great biotic American interchange shaping current Neotropical biodiversity (Bacon et al., 2015).

Phylogenetic methods now make possible the investigation of the relative contributions of phenotypic traits and biogeographic events on the evolutionary history of different groups of organisms (Pinto-Sanchez et al., 2012; Weir et al., 2009). Combining knowledge of phylogenetic relationships, the timing of diversification and trait and distribution data permits testing of competing hypotheses about the origin and evolutions of diverse biotas (Mullen et al., 2011), and identifies traits that might have had a crucial role in the evolutionary history of organisms (Losos et al., 1997).

Butterflies are an excellent model system for the study of color evolution and the influence of geographic events on diversification. Color pattern alone can be used to distinguish most of the 18,000 described butterfly species (Nijhout, 1991). The most studied functions of color include mimicry, predator avoidance, mate recognition and sexual selection, and these functions are thought to have influenced diversification (Chazot et al., 2014; Jiggins, 2008; Kemp, 2007; Obara \& Majerus, 2000). Similarly, novel habitats and barriers to dispersal created by Neotropical landscape rearrangement have influenced the evolution of a number of butterfly groups (Chazot et al., 2019, 2016; Condamine et al., 2012; De-Silva et al., 2017, 2016; Toussaint et al., 2019). The increasing availability of comprehensive dated phylogenetic hypotheses for butterflies (Chazot et al., 2020; Espeland et al., 2018) allows a more rigorous study of how different, and potentially conflicting, functions of color have generated trait and species distributions and diversity (Finkbeiner et al., 2014). Phylogenies also enable tests of how shifts in color pattern, in concert with changes in geographic range and habitat, have influenced speciation and diversification (Chazot et al., 2014; Jiggins et al., 2006).

The Neotropical region contains approximately $45 \%$ of species in the family Nymphalidae, the most species rich family of butterflies (Chazot et al., 2020). The Nymphalidae contains such morphologically diverse groups of species that many currently recognized subfamilies were once treated as families. The family ranges from the often small and drab Satyrinae to some of the largest and most spectacularly colored butterflies, of which the Neotropical tribe Preponini (Charaxinae) is renowned as one of the most outstanding examples. Preponini butterflies inhabit the forest canopy and are characterized by robust bodies and erratic flight. They are distributed from Mexico to Argentina, with a species richness peak in the Amazon basin. Wing color patterns among Preponini species exhibit a dramatic transition from dorsally blue and ventrally brown to dorsally red/orange and ventrally multicolored (Figure 1). This color pattern variation explains why some Prepona species were long classified in a separate genus, Agrias ( Ortiz-Acevedo et al., 2017). The bright color patterns of preponines have attracted the attention of collectors and naturalists for over two centuries, resulting in hundreds of names for species withinPrepona in particular (Lamas, 2004). Lamas (2004) recognized 22 species in the tribe, but subsequent additions and revisions has resulted 25 described species are now recognized, distributed in three genera Archaeoprepona, Mesoprepona and Prepona(OrtizAcevedo et al., 2017; Turrent Carriles and García Días, 2019). Nevertheless, no study to date has focused on understanding the role of color and biogeography on the diversification of this group.

In this study, we attempt to understand to what extent coloration and biogeographical events may have shaped the diversity of the tribe by quantifying color change, diversification rates and estimating ancestral geographical ranges. We hypothesize that the main driver of Preponini evolution is color shifts, but biogeographical events in the last $30 \mathrm{Ma}$ also likely influenced the origins of particular clades. Given that the members of Prepona show drastic changes in color patterns, we hypothesize that there might be a congruence between shifts in diversification and phenotypic evolutionary rates. Similarly, we expected that changes in diversification rates might be associated with major landscape changes, such as the Andes uplift and final closure of the Panama Isthmus.

Materials and Methods 


\section{Phylogeny and divergence time estimation}

We used DNA sequence data from Ortiz-Acevedo et al. (2017). The final matrix comprises sequences from two mitochondrial and four nuclear gene fragments from 29 Preponini specimens including 24 of the 25 generally recognized species and five representatives of geographically and/or morphologically distinct populations of Prepona deiphile and $P$. laertesthat we currently consider as distinct species (Neild, 1996; Turrent Carriles and García Días, 2019, Llorente et al. in prep, Ortiz-Acevedo et al. in prep.). We used as outgroup the sister tribe Anaeomorphini (Espeland et al., 2018). Out of Preponini and Anaeomorphini, our taxon sample excludes only the recently described Prepona silvana from western Mexico, apparently a close relative of what we refer to as P. deiphile (CA), and P.'sahlkei', treated by Neild (1996) as a distinct species from the Guianas but as synonym of $P$. claudina claudina by Lamas (2004), and whose status is currently uncertain (Table S1).

We partitioned the data by codon position a priori, and then searched for the optimal partitioning scheme using the greedy algorithm in PartitionFinder v2.1.1 (Lanfear et al., 2012) (Table S2). Phylogenetic relationships and divergence times were inferred simultaneously using BEAST 2.4.5 (Bouckaert et al., 2014). The clock prior was set to an uncorrelated relaxed lognormal distribution, and site models were co-estimated with the phylogeny using reversible jump by applying the bModelTest 0.3.3 plugin (Bouckaert and Drummond, 2017). Site models were unlinked and tree models were linked. We ran three different analyses that differed in the number of molecular clocks used. The models consisted of i) two molecular clocks, one for all mitochondrial partitions and the other for all nuclear partitions ii) multiple clocks, one for all mitochondrial partitions and one for each nuclear partitions iii) multiple molecular clocks, one for each partition).

The tree prior was set to a Yule model. The birth rate prior was set to uniform with the lower boundary of 0 and upper of 1,000 and the prior for the mean rate under the uncorrelated lognormal relaxed molecular clock (ucldMean) was set to a gamma distribution with alpha of 0.01 and beta of 1,000 . We used a secondary calibration point for the common ancestor node for Preponini+Anaeomorphini assuming a normal prior distribution with mean at $32.9 \mathrm{Ma}(95 \%$ credibility interval $\mathrm{CI}=22.0-42.3 \mathrm{Ma})$ and sigma of 4.0 (Espeland et al 2018). The value of sigma was selected to include the error associated with the primary dating study and incorporating the credibility interval estimated for the node Preponini+Anaeomorphini in the calibration (Forest, 2009). Three individual runs of 100 million generations were performed, sampling every 10,000 generations. The runs were combined in LogCombiner 2.4.5 and convergence was assessed in Tracer v1.6 (Rambaut et al., 2014). From the combined runs we subsampled a total of 10,000 trees using LogCombiner to infer a maximum credibility tree in TreeAnnotator 2.4.5.

We used path sampling and stepping-stone sampling to estimate the marginal likelihoods of the different molecular clock analyses (Baele et al., 2013) and used Bayes Factors (Fan et al., 2011) to select the best analysis. We used 100 steps with a chain length of 1 million generations and other settings were kept as default, and tested convergence by examining that the average standard deviation of split frequencies fell below 0.01 , visually inspecting the trace files in Tracer v1.6 (http://tree.bio.ed.ac.uk/software/tracer/) and checking that the effective sample size values for parameters were higher than 200.

\section{Wing color pattern evolution}

To reconstruct ancestral color patterns and estimate their rate of evolution we photographed museum specimens deposited at the McGuire Center for Lepidoptera and Biodiversity, Florida Museum of Natural History (MGCL-FLMNH) collection. We sampled on average 12 individuals per species, but some species, such as Prepona amydon $(\mathrm{n}=61)$, had higher sampling due to their phenotypic diversity. We reduced possible color pattern variation caused by adverse collection storage conditions by selecting as recently collected specimens as possible (Figure S1).

Photographs in JPEG format were taken using a standardized light box setup. Color was measured at three independent locations on the forewing as well as over the forewing as a whole. The three forewing locations included the discal cell (Cell 1), and the regions delimited by the discal cell and the veins $\mathrm{M}_{1}$ and $\mathrm{M}_{2}$ (Cell 2), and $\mathrm{CuA}_{1}$ and $\mathrm{CuA}_{2}$ (Cell 3) (Figure S2). Those regions were selected to represent regions containing the 
most significant observed variation in color across the forewing and to control for differences in wing size. On each of the wing regions and for the whole wing we measured the mean and mode of the red, green, and blue channels (RGB) as well as total RGB values using ImageJ (Abramoff, 2004; Rasband, 1997; Schneider et al., 2012). In total, we measured color as a set 32 traits, 16 based on the mean and 16 on the mode. We considered both, the mean and the mode, because the mode in a skewed distribution describes better where the bulk of the density is concentrated while the mean may deviate from the mode because of large numbers in the tails of the distribution. Since we wanted to test for differences in evolutionary rates and the signature of evolution in the three different cells as well as the overall wing, we did not attempt to reduce the variable set by means of principal component analysis. Additionally, since Preponini consists of three genera in two clades, one mainly blue and the other blue and red, we wanted to evaluate the rates of evolution of the different color channels independently.

To test for changes in evolutionary rates in color across lineages, we used the function rjmcmc.bm in the package 'geiger 2.0' (Harmon et al., 2008) in $\mathrm{R}$ which implements a Bayesian approach using a reversible jump Markov chain Monte Carlo (rjMCMC) process to compare among four different models of changes in evolutionary rates (Eastman et al., 2011). The first was a single rate Brownian motion (BM) model in which phenotypic rate evolution was constant across the tree. Next, we fitted a relaxed BM model (rBM1) in which evolutionary rates were allowed to shift multiple times across trees. Third, we kept evolutionary rates constant (no shift), but traits were allowed to pulse rapidly, representing jumps in the mean of the trait (jump-BM). Last, we combined rBM1 and jump-BM to allow phenotypic rates to shift several times and the mean trait to jump across the tree (jump-rBM, Eastman et al., 2011). Before running the models, we calibrated the rjMCMC and estimated that the most reasonable proposal width to initiate sampling of the Markov chain was eight for both mean and mode and for every model evaluated (see Eastman et al., 2011).

Model selection was performed using the Akaike Information Criterion (AIC) for MCMC samples (Raftery et al., 2007). The difference in AIC ( $\Delta$ AIC) between models was used to select the best model. We assumed a model to be significantly better than another if $\Delta$ AIC $>2$. In the case in which $\Delta$ AIC $<2$, we selected the simplest model in the following order: 1) BM, 2) rBM1, 3) jump-BM and 4) jump-rBM. We did not perform model averaging in cases in which $-2<\Delta \mathrm{BIC}<2$, because it has been suggested to be misleading (Taper and Ponciano, 2016).

For each model in each cell and measurement, we ran two chains each for 1250000 generations sampling every 1000. We assessed convergence of the MCMC by inspecting the trace of each parameter and estimating the effective sample size. Finally, we used maximum likelihood ancestral state reconstruction to visualize trait evolution (Felsenstein, 2004) using the ace function in 'ape' (Paradis et al., 2004) in R.

\section{Diversification dynamics estimation}

To investigate if diversification rates varied through time we used a series of likelihood-based diversification models in the R package RPANDA (Morlon et al., 2016). One of the models implemented in RPANDA estimates the likelihood that speciation and extinction are constant or variable through time. Accordingly, we tested a combination of models in which we allowed speciation and extinction to be either constant or variable following a linear or an exponential model (see Table 1 for model specification and results for details on linear models). We compared the models using AIC.

In addition to the RPANDA time dependent diversification analyses, we used alternative methods to support the estimation of diversification rates for the tribe. Overall, we estimated diversification rates using the Constant-Rates test (CRT; Pybus and Harvey, 2000), Magallón and Sanderson's estimator (Magallon and Sanderson, 2001), and Bayesian Analysis of Macroevolutionary Mixtures (BAMM; Rabosky, 2014) and MEDUSA (Alfaro et al., 2009), and visualized the results with a lineage through time plot (LTT). See detail about these diversification analyses in the Appendix.

Trait dependent diversification analyses 
To test whether Preponini lineage diversification has been dependent on phenotypic evolution (i.e. color pattern), we used the Equal-Splits with Simulated null model (ES-sim) method (Harvey and Rabosky, 2018). ES-sim employs a tip and rate correlation technique to test for the significance of the correlation between trait values at the tips and the phylogeny's branching pattern in the absence of an evolutionary model. Harvey and Rabosky (2018) showed that for phylogenies with ${ }^{\sim} 50$ species, ES-sim performed better in the Type I error rate and had comparable power to QuaSSE (Quantitative State Speciation and Extinction, FitzJohn, 2010), a method commonly used to jointly model diversification and the change in continuous traits. In addition, ES-sim is useful for small phylogenies with few and slight changes in diversification rate, which might be the case in our study (Harvey and Rabosky, 2018). As a result of the ES-sim test, we obtained i) a Pearson's correlation coefficient (rho), which quantifies the strength of the relationship between traits and each lineage's diversification rate and ii) the simulation-based two tailed probability value (p-value) which allows comparison of the data to a null hypothesis.

\section{Biogeographic dependent diversification analyses}

To test if the Andean uplift or closure of the Panama Isthmus influenced Preponini diversification rates we used a similar likelihood approach as for time dependent diversification analyses implemented in RPANDA. In this case, we evaluated the fit of six models allowing speciation and extinction rates to be dependent on the paleo-elevation of the Andes (three models) or the degree of connectivity between Central and South America (three models; Morlon, 2014; Morlon et al., 2011; see Table 1).

We used Andean paleo-elevation from present time until $32 \mathrm{Ma}$ based on the database provided by Lagomarsino et al. (2016) and information from Garzione et al. (2008). The closure of the Panama Isthmus was estimated using reports of migration rates for several groups of organisms by Bacon et al (2015). In the latter study they reported that migration rates between the two continents increased sequentially at four points in time, 41.1, 23.7, 8.7 and 5.2 Ma. We used these migration rate estimates to compute the probability of observing at least one migration event in each time period (i.e. 50 - 41.1, 41.1 - 23.7, $23.7-8.7,8.7$ - 5.2, 5.2 - present). We then used the cumulative probability through time to observe at least one migration event per million years as a proxy of the degree of connectivity between land masses (Table S3).

\section{Estimation of ancestral ranges}

We used a Microsoft Access database to compile locality data from 4050 Preponini specimens deposited at five butterfly collections: the McGuire Center for Lepidoptera and Biodiversity, Florida Museum of Natural History, University of Florida (Gainesville, FL, USA), National Museum of Natural History, Smithsonian Institution (Washington D.C., USA), American Museum of Natural History (New York, NY, USA), Instituto Alexander von Humboldt (Villa de Leyva, Colombia), and the Instituto de Ciencias Naturales - Universidad Nacional de Colombia Sede Bogotá (Bogotá, Colombia). We georeferenced localities using Google Earth, literature and published/unpublished gazetteers, and cleaned the database to remove erroneous and imprecise localities. Our final database contained 1121 locality records for the 31 taxa in consideration.

We used the R package BioGeoBEARS 1.1.1 (Matzke, 2018) to estimate the ancestral range of Preponini under the Dispersal-Extinction Cladogenesis (DEC) model (Ree and Smith, 2008) and a maximum likelihood implementation of the Dispersal-Vicariance analysis (DIVALIKE) model (Ronquist, 1997). We did not include models with the parameter J since they seem less relevant to continental settings and have been shown to be difficult to compare statistically to other non-nested models (Ree \& Sanmartín, 2018). We tested eight different hypotheses to evaluate the influence of different biogeographic events and distance among areas in the evolutionary history of Preponini (see Table 2 for details).

Briefly, the hypotheses account for the influence of the closing of the Panama isthmus, the formation of the Andes and distance among eight geographic areas in the Neotropics. We coded the areas as Central America, Caribbean, Chocó and Caribbean lowlands, Western Andes, Eastern Andes, Amazon (including Chaco and Cerrado), Guianas, and Atlantic Forest, are based on NatureServe's classification of the Neotropics into 'Ecological Systems' (Josse, 2003). Since one of our objectives was to test for the influence of major biogeographical events, we designated four time slices representing different paleo-geological stages. The four 
time slices used in our analyses were: (1) 32-23; (2) 23-10 Ma , (3) 10-7 Ma, and (4) 7 Ma-present which represent the gradual formation of the connection between South and Central America and Andean Uplift (Bacon et al., 2015; Condamine et al., 2012; Montes et al., 2015). We allowed the probability of movement across areas to change in time, accounting for geographic position, distance and for barriers to dispersal, and penalized accordingly (Table S4 - S11). We evaluated the effect of distance by penalizing dispersal probabilities with a factor proportional to the distance among the centroids of the areas (Table S5, S8, S9, S11).

Both DEC and DIVA are biased towards estimating widespread ranges in deep nodes (Buerki et al., 2011; Clark et al., 2008; Matzke, 2014; Ree and Smith, 2008). In an attempt to avoid this potential bias, the maximum number of areas any ancestor may occupy was set to six, since this is the maximum number of areas observed to be currently occupied by any single Preponini species (Ronquist and Sanmartin, 2011; e.g.Archaeoprepona demophoon ). We reduced the number of potential ranges in the reconstruction by including only geographic ranges with adjacent areas. This resulted in 113 potential ranges from the 248 possible combinations. To identify the hypotheses with strongest support, we compared AIC among the eight hypotheses and two possible models.

Results

\section{Phylogeny and divergence time estimation}

The three analyses with different molecular clocks were equally supported $(\mathrm{BF}=\sim 1$, Table S12, Table S13). The phylogenetic reconstruction is mostly congruent with published topologies and has good support overall (Figure 2, 3 Figure S3) (Ortiz-Acevedo et al., 2017; Ortiz-Acevedo and Willmott, 2013). The origin of Preponini was estimated at $\sim 27.6 \mathrm{Ma}$ in the Oligocene, that of Archaeoprepona and Mesoprepona in the mid-Miocene $\sim 13 \mathrm{Ma}$, and Prepona in the late Miocene $\sim$ Ma (Figure 2, 3 Figure S3). The red Preponaclade originated in the early Pliocene, $\sim 5$ Ma.

\section{Wing color pattern evolution}

Although the overall signature of evolution suggests constant phenotypic evolutionary rates, for both mean and mode, we identified two jumps in evolutionary rate in the red channel Cell 1 in the red Preponaclade; the first one at the base of the red Prepona clade and the second along the branch leading to Prepona hewitsonius (Table 3, Figure 2, Figure S4-S5). The blue channel in Cell 2 showed between 1 and 3 jumps (mean and mode, respectively; Posterior Probability $>0.5$ ). These jumps are located at the base of the $P$. hewitsonius $+P$. amydon clade, at the branch leading to $P$. hewitsonius (mean and mode), and at the tip leading to P. philipponi (W) (Figure 2, Figure S4-S5). There was discrepancy between mean and mode in only one case, the mode identified a jump in the total channel in Cell 1 (Table 3, Figure 2, Figure S4-S5) located at the base of the red Prepona clade.

\section{Diversification dynamics estimation}

The RPANDA analyses identified the time dependent model with constant speciation and no extinction, and with exponentially varying speciation, as the best models (Table 1). The first model suggests speciation rate to be 0.12 species per Ma. In the second model, which has support similar to the constant diversification model, speciation increases through time from 0.05 at $32 \mathrm{Ma}$ to 0.15 species per Ma in the present. However, we give more support to the former model because it has fewer parameters. Models assuming linearly varying speciation and extinction did not converge, consequently we do not show the results here. Most other complementary diversification analyses agree with the constant diversification rate model, except MEDUSA (Appendix).

\section{Trait dependent diversification analyses}

We found that diversification rate was not dependent on any of the color traits. We found that the absolute value of Pearson's rho was smaller than 0.54 for the mean and mode of color for all cells and the full wing, 
suggesting low correlation between the equal splits (ES) and trait values (Table 4). Furthermore, none of the Pearson's rho was significantly different from the null expectation.

\section{Biogeographic dependent diversification analyses}

Diversification models accounting for the influence of biogeographical events on the diversification rates of Preponini suggest that speciation and both the Andean uplift and the closure of the Panama isthmus were exponentially and positively correlated through time (Table 1). In fact, the model with exponentially varying speciation rate depending on Andean uplift had a slightly lower AIC than the time dependent models (Table 1).

\section{Estimation of ancestral ranges}

BioGeoBEARS analyses identified DEC as the best model with restriction to dispersal and an influence of the closure of the Panama Isthmus and Andean Uplift (Ho7) as the hypothesis with strongest support (Figure 3, Table 5). The tribe most likely originated in South America (node I in Figure 3, Figure S6). The genus Archaeoprepona retained its ancestor's range of origin (node II in Figure 3); other ranges with high probability also suggest a continental America origin (Figure S6). Similarly, Mesoprepona+Prepona likely originated in South America (node III; Figure 3); the other probable regions of origin comprise broad ranges as for its sister genus (Figure S6). The origin of Prepona was most likely in mainland South America, excluding high elevation habitats of the western Andes (node IV; Figure 3). Finally, the clade that corresponds to the transition of color patterns from mostly blue to red Prepona species was found to have most likely originated in the Amazon and Eastern Andes (node V; Figure 3, Figure S6); the other ranges with high probability are narrow, where Andes, Amazon or Chocó are also likely regions of origin (Figure S6).

\section{Discussion}

In our study we hypothesized that shifts in color patterns and/or biogeographical events have contributed to Preponini diversification. We also hypothesized that the tribe originated in the Amazon basin, given its high species richness in this region. Despite finding high rates of wing color evolution, mostly in the red Prepona clade (Figure 2; Node V in Figure 3), we found that diversification rates in Preponini were not dependent on color evolution. However, major landscape reconfiguration, happening through most of the tribe's evolutionary history, did seem to influence speciation rates and distribution patterns (Table 1 for models of biogeography dependent diversification analysis results). The Panama Isthmus and the uplift of the Andes mountain range together contributed most to the distribution patterns of extant Preponini. Cladogenesis happened mostly through dispersal to new ranges or splitting of broadly distributed taxa, as suggested by the Dispersal Extinction Cladogenesis model (DEC; Table 5), and Preponini likely originated within South America.

\section{Wing color pattern evolution}

During the course of their evolution, Prepona underwent drastic changes in the color pattern of both wing surfaces (Figures 2-3). These color patterns were the key features used by previous taxonomists to classify Prepona species in two genera. The former genusAgrias contained yellow, orange, blue and red species andPrepona, as delimited previously, contained mostly blue species. The former group being nested within the latter is supported by molecular and morphological data (Ortiz-Acevedo et al., 2017), while color patterns apparently transitioned rapidly from blue to red (Figure 2), resulting in Prepona containing butterflies with such strikingly different coloration patterns (Figures 1-3).

Our results suggest that there is stronger change in phenotype for red and blue RGB channels (Table 3) than for green and total RGB. The changes identified are mostly jumps in the mean and are located around the red Prepona clade (Figure 2). The analysis consistently identified the jump from blue to red in Cell 1 with no shift in the rate of evolution. Despite the fact that the red Prepona clade is so notably different in color pattern compared to the rest of the tribe's members, the evolutionary rate of phenoptyic change after the jump remained similar to that in blue clades. These jumps are consistent with previous findings, that drastic changes in color patterns of butterfly wings and other organisms have a relatively simple genetic basis and 
can appear relatively fast in evolutionary time (Nadeau et al., 2016; Reed et al., 2011). Differential genetic expression in particular regions of the wing are also responsible for localized changes (Brakefield et al., 1996; Nadeau et al., 2016; Oliver et al., 2012), which might be a plausible explanation for the results we found in Cell 1. These localized changes are not always visible under analysis of the entire wing, thus, isolating those regions that are likely to change quickly allowed us to detect the jumps in phenotype.

Jumps and shifts in the blue channel are restricted to the tips of the phylogeny and might be associated with recent speciation events. For example, we identified two jumps in the blue channel of Cell 2 (Figure 2); i) in the branch leading to Prepona amydon $+P$. hewitsonius and ii) in P. hewitsonius. These species are phenotypically extremely diverse in forewing coloration, ranging from dark, deep blue to light, bright blue, even within subspecies (Figure S7). We also identified a change in the Cell 3 blue channel at the branch leading to Prepona philipponi $(W)$. Prepona philipponi $(W)$ has a different light blue tone compared to $P$. philipponi (E) (Figure S8), but with only a single studied individual of the former taxon, this result needs corroborating with further samples.

A potential explanation for the dramatic change of color patterns in Preponini is involvement in mimicry rings with genera such as Callicore and Asterope (Nymphalidae, Biblidinae), which have remarkably similar color patterns on both wing surfaces (Descimon, 1977; Jenkins, 1987; Figure S9). The inferred origin of the red clade in Preponapartially supports this hypothesis, since both Callicore and Asterope are predominantly Andean and Amazonian groups. In particular, the red Prepona showed no change in the Amazonian ancestral range as it underwent speciation (Figure 3). Mimicry is plausible since species in both groups feed on toxic plants, including the families Sapindaceae and Erythroxylaceae, but whether they sequester plant toxins as caterpillars and retain them after emerging as adults is still unknown, as is their palatability. Preliminary geographical distribution data show a correspondence in coloration and distribution among Prepona, Callicore and Asterope(Ortiz-Acevedo et al., in prep.).

\section{Diversification of Preponines}

In studies of other Neotropical butterfly groups, natural history traits and paleo-climatic events have been shown to shape diversification rates by influencing speciation and/or diversification (Chazot et al., 2020; De-Silva et al., 2016; Sahoo et al., 2017). This seems to be the case for Preponini as well. Our likelihoodbased diversification rate analyses suggest a constant diversification rate over $30 \mathrm{Ma}$ and is mostly congruent among alternative methods (Appendix). The diversification rate estimated by our likelihood analysis (0.12) is within the range of diversification rates estimated for other butterfly groups (Chazot et al., 2020; Peña and Espeland, 2015). However, we found support for exponentially varying speciation rates, similar to speciation rates in Neotropical Nymphalidae (Chazot et al., 2020). Extinction in the three top candidate models was $a$ priori fixed to zero, as estimated for larger Neotropical butterfly clades during the same geological time (Chazot et al., 2020).

Our analyses support an exponential increase of speciation promoted by the Andean uplift (Table 1). In fact, this biogeographically dependent model has slightly higher support than the time dependent models discussed above. A similar result has been found in many other organisms, both lowland and highland, and is hypothesized to result from the ecological opportunity created by emergence of new niches and the restriction of dispersal across the Andes (Smith et al 2014). Our ancestral range estimates show that, after the two last pulses in Andean uplift, lineages mostly contracted in their ranges leading to allopatric sister clades. For example, the ancestor of the clade containing Archaeoprepona licomedes, A. priene and A. chromusmost likely had an eastern Andean distribution, while its sister clade had a probable Central American ancestor (Figure 3). Also, the clade containing all Prepona species except $P$. dexamenusoriginated from a Chocoan ancestor, and one daughter lineage retained its ancestral range while the other dispersed to the Amazon, Guianas and Atlantic forest (Figure 3). The origin of many recent Preponini species dates to a time of intensified Andean uplift, in which the Pebas system started to drain and the Amazon river reached its current configuration, aided by the formation of the Acre system (Hoorn et al., 2010). The Miocene-Pliocene boundary was also characterized by a global vegetation change (Cerling et al., 1997). 
A recent study showed that phylogenetic trees alone do not have enough information to tease apart different evolutionary scenarios since particular topology can either result from high speciation and constant extinction or decreased extinction and constant speciation (Louca and Pennell, 2020). Consequently, we would expect similar support for those alternative scenarios. Here we show however that the support for models with constant speciation and no extinction or exponentially increasing speciation with no extinction is considered to be much stronger than the models with constant speciation and decreasing extinction under an evidential statistics framework (Taper and Ponciano, 2016).

\section{Origin and Biogeographical Patterns}

Although the high Amazonian species richness of the tribe would suggest an out-of-the-Amazon biogeographical model, the tribe Preponini originated from a widespread South American ancestor at $27.5 \mathrm{Ma}$ in the early Oligocene. By this time, South America, dominated by forests (Strömberg et al., 2013), detached from Antarctica and moved north towards North America (Axelrod et al., 1991). This dating is consistent with other studies that used independent datasets (Peña and Wahlberg, 2008; Wahlberg et al., 2009). Members of Preponini likely dispersed, colonized and diverged in new niches in Central America as the bridge between land masses became more continuous at $\sim 23 \mathrm{Ma}$ (Bacon et al., 2015; Montes et al., 2015). This event has been demonstrated to have played a major role in the diversification of multiple groups of organisms (Bacon et al., 2015).

It has been suggested that some of methods for ancestral range reconstruction are biased towards estimating widespread ancestral ranges (Buerki et al., 2011; Clark et al., 2008; Matzke, 2014; Ree and Smith, 2008), as we found in the ancestor of Preponini. To reduce this bias, we restricted the ancestral estimate to contain only six of the eight areas considered, as observed in the most widespread extant Preponini species (Ronquist and Sanmartin, 2011, i.e.Archaeoprepona amphiachus, A. demophoon, A. demophon ). In addition, climatic changes accompanying the evolution of Preponini make biological sense in light of our inferred ancestral range estimate, as we discuss below.

Early speciation events in the tribe are characterized by range maintenance ( $~ 13 \mathrm{Ma}$; Nodes II and III; Figure 3).Subsequently, the ancestor of Archaeoprepona contracted in range, becoming restricted to the Atlantic forest region and subsequently dispersing to the Chocó. The transition from Atlantic Forest to Chocó happened through an anagenetic expansion including all South American areas except Western Andes and a subsequent range contraction (Table S15). The restriction of the ancestor of Archaeoprepona to Atlantic forest is coincident with a period in which tropical forests in South America were likely reduced by a decrease in global temperature (Kürschner et al., 2008; Pound et al., 2011). The late Miocene was probably characterized by grassland habitats, as suggested by high diversification of hoofed animals and changes in their dentition (Kürschner et al., 2008). Preponini species are not currently known to inhabit these grassland habitats. The subsequent dispersal to the Chocó follows an increase in global temperature and the reappearance of widespread tropical forests (Kürschner et al., 2008; Pound et al., 2011).

After the colonization of Chocó tropical forests, Archaeopreoponadispersed to central America at $\sim 8$ Ma during periods of intensified biological migration between Central and South America (Bacon et al 2015). From this point forward, high geologic activity in South America during the Pliocene (Hoorn et al., 2010) likely promoted dynamism in current ranges in which some species became widespread (clades containing Archaeoprepona demophoon and A. amphimachus), while other became restricted (e.g A. chromus and A. priene ) to small geographic areas.

Conversely, Prepona + Mesoprepona, which originated from a South American ancestor, shows contrasting patterns of range evolution.Mesoprepona, a monotypic genus, shows a reduction of its distribution range and became restricted to eastern South America. In contrast, the relatively species-rich Prepona shows early diverging clades to have dispersed to a larger area, including South and Central America, around a time of increased migration between these two continents (Bacon et al., 2015). The early branching Prepona laertes clade was found to be initially restricted to eastern South America, with subsequent dynamism in range contraction/expansion as it underwent speciation events. More recent clades were found to have contracted 
their ranges at $\sim 7 \mathrm{Ma}$, becoming restricted to the Chocó region, while the Amazon region suffered landscape reconfiguration resulting from the transition of the Pebas system to the Acre system.

The subsequent speciation events show: i) range maintenance in the restricted Prepona werneri, ii) range expansion followed by contraction in the $P$. pylene and $P$. deiphile clade, and iii) slight range expansion followed by contraction in the redPrepona clade (Node III, Figure 3). The dynamic range evolution in these clades happened in the early Pliocene $\sim 5 \mathrm{Ma}$, which is characterized by landscape reconfiguration due to a strong activity in Andean uplift (Hoorn et al., 2010; Figure 3). This intensified final uplift of the Andes likely allowed the earliest divergent red Prepona to shift from lowland-highland distribution and become restricted to higher elevation habitats, while the ancestor of the remaining red Prepona species became restricted to the Amazonian lowlands. Current distribution ranges of the taxa in this clade show expansion of their ranges to eastern South America and dispersal to habitats west of the Andes.

Other examples of the influence of the Andean uplift on speciation and range dynamics of Prepona clades is exemplified in the clade containing $P$. pylene, $P$. eugenes, $P$. gnorima and $P$. deiphile. Recent phylogenetic reconstructions and morphological analyses of the tribe split the previously widespread Prepona pylene (sensu Lamas, 2004) intoP. pylene, P. eugenes and P. gnorima . Our dating suggests that Prepona gnorima, distributed in Central America and Chocó, split from the eastern South American P. pylene +P. eugenesat $\sim 5$ Ma. Furthermore, Prepona deiphile, although currently considered a widespread species, is paraphyletic in our phylogeny, supporting a split into a Central American and South American clade(Ortiz-Acevedo et al., 2017; Turrent Carriles and García Días, 2019) that probably happened during the last pulse of Andean uplift.

Preponini genera exhibit contrasting biogeographical histories, suggesting that they might have evolved under different evolutionary pressures and scenarios. Differences in natural history, and in particular larval host plant relationships, potentially underlie these differing biogeographical patterns as demonstrated in the closely related Neotropical charaxine tribe Anaeini for instance (Toussaint et al., 2019). Unfortunately, knowledge of host plants in Preponini is still rather incomplete, although, researchers, collectors and enthusiasts are working together to fill this gap in knowledge.

Conclusions

This first investigation of color pattern evolution in Preponini posits new hypotheses for the observed shifts across the phylogeny of the group. We found that, contrary to what might have been expected, changes in wing color did not influence diversification rates in this group. Both the formation of the Isthmus of Panama and the uplift of the Andes mountain range positively impacted the diversification of Preponini. Landscape reconfiguration and ecological opportunity created by the complex emergence of the connection between Central and South America and mountain building allowed dispersal, colonization and divergence in newly available niches. Further studies should focus on the mechanisms that triggered the striking change in color that happened rapidly in the genus Prepona. In particular, Prepona are potentially involved in mimicry rings with Callicore and Asterope, which also show a high richness in the Amazon region, with a number of species restricted to this area.

\section{References}

Abramoff, M.D., 2004. Image Processing with ImageJ. Biophotonics International 11, 36-42.

Alfaro, M.E., Santini, F., Brock, C., Alamillo, H., Dornburg, A., Rabosky, D.L., Carnevale, G., Harmon, L.J., 2009. Nine exceptional radiations plus high turnover explain species diversity in jawed vertebrates. P Natl Acad Sci USA 106, 13410-13414. https://doi.org/10.1073/pnas.0811087106

Antonelli, A., Zizka, A., Carvalho, F.A., Scharn, R., Bacon, C.D., Silvestro, D., Condamine, F.L., 2018. Amazonia is the primary source of Neotropical biodiversity. PNAS 115, 6034-6039. https://doi.org/10.1073/pnas.1713819115

Axelrod, D.I., Kalin Arroyo, M.T., Raven, P.H., 1991. Historical development of temperate vegetation in the 
Americas. Revista Chilena de Historia Natural 64, 413-446.

Bacon, C.D., Silvestro, D., Jaramillo, C., Smith, B.T., Chakrabarty, P., Antonelli, A., 2015. Biological evidence supports an early and complex emergence of the Isthmus of Panama (vol 112, pg 6110, 2015). P Natl Acad Sci USA 112, E3631-E3631. https://doi.org/10.1073/pnas.1511204112

Baele, G., Li, W.L.S., Drummond, A.J., Suchard, M.A., Lemey, P., 2013. Accurate Model Selection of Relaxed Molecular Clocks in Bayesian Phylogenetics. Mol Biol Evol 30, 239-243. https://doi.org/10.1093/molbev/mss243

Berthier, S., 2005. Thermoregulation and spectral selectivity of the tropical butterfly Prepona meander : a remarkable example of temperature auto-regulation. Applied Physics A 80, 1397-1400. https://doi.org/10.1007/s00339-004-3185-x

Bouckaert, R., Heled, J., Kuhnert, D., Vaughan, T., Wu, C.H., Xie, D., Suchard, M.A., Rambaut, A., Drummond, A.J., 2014. BEAST 2: A Software Platform for Bayesian Evolutionary Analysis. Plos Comput Biol 10. https://doi.org/10.1371/journal.pcbi.1003537

Brakefield, P.M., Gates, J., Keys, D., Kesbeke, F., Wijngaarden, P.J., Montelro, A., French, V., Carroll, S.B., 1996. Development, plasticity and evolution of butterfly eyespot patterns. Nature 384, 236. https://doi.org/10.1038/384236a0

Buerki, S., Forest, F., Alvarez, N., Nylander, J.A.A., Arrigo, N., Sanmartin, I., 2011. An evaluation of new parsimony-based versus parametric inference methods in biogeography: a case study using the globally distributed plant family Sapindaceae. J Biogeogr 38, 531-550. https://doi.org/10.1111/j.1365-2699.2010.02432.x

Cerling, T.E., Harris, J.M., MacFadden, B.J., Leakey, M.G., Quade, J., Eisenmann, V., Ehleringer, J.R., 1997. Global vegetation change through the Miocene/Pliocene boundary. Nature 389, 153. https://doi.org/10.1038/38229

Chazot, N., Condamine, F.L., Dudas, G., Peña, C., Matos-Maraví, P., Freitas, A.V.L., Willmott, K.R., Elias, M., Warren, A., Aduse-Poku, K., Lohman, D.J., Penz, C.M., DeVries, P., Kodandaramaiah, U., Fric, Z.F., Nylin, S., Müller, C., Wheat, C., Kawahara, A.Y., Silva-Brandão, K.L., Lamas, G., Zubek, A., Ortiz-Acevedo, E., Vila, R., Vane-Wright, R.I., Mullen, S.P., Jiggins, C.D., Slamova, I., Wahlberg, N., 2020. The latitudinal diversity gradient in brush-footed butterflies (Nymphalidae): conserved ancestral tropical niche but different continental histories. bioRxiv 2020.04.16.045575. https://doi.org/10.1101/2020.04.16.045575

Chazot, N., Willmott, K.R., Condamine, F.L., De-Silva, D.L., Freitas, A.V.L., Lamas, G., Morlon, H., Giraldo, C.E., Jiggins, C.D., Joron, M., Mallet, J., Uribe, S., Elias, M., 2016. Into the Andes: multiple independent colonizations drive montane diversity in the Neotropical clearwing butterflies Godyridina. Mol. Ecol. 25, 5765-5784. https://doi.org/10.1111/mec.13773

Chazot, N., Willmott, K.R., Endara, P.G.S., Toporov, A., Hill, R.I., Jiggins, C.D., Elias, M., 2014. Mutualistic Mimicry and Filtering by Altitude Shape the Structure of Andean Butterfly Communities. The American Naturalist 183, 26-39. https://doi.org/10.1086/674100

Chazot, N., Willmott, K.R., Lamas, G., Freitas, A.V.L., Piron-Prunier, F., Arias, C.F., Mallet, J., De-Silva, D.L., Elias, M., 2019. Renewed diversification following Miocene landscape turnover in a Neotropical butterfly radiation. Global Ecology and Biogeography 28, 1118-1132. https://doi.org/10.1111/geb.12919

Clark, J.R., Ree, R.H., Alfaro, M.E., King, M.G., Wagner, W.L., Roalson, E.H., 2008. A Comparative Study in Ancestral Range Reconstruction Methods: Retracing the Uncertain Histories of Insular Lineages. Syst Biol 57, 693-707. https://doi.org/10.1080/10635150802426473

Condamine, F.L., Silva-Brandao, K.L., Kergoat, G.J., Sperling, F.A.H., 2012. Biogeographic and diversification patterns of Neotropical Troidini butterflies (Papilionidae) support a museum model of diversity dynamics for Amazonia. Bmc Evol Biol 12. https://doi.org/10.1186/1471-2148-12-82 
Darwin, C., 1880. The sexual colors of certain butterflies. Nature 21, 237.

Darwin, C., 1874. The descent of man and selection in relation to sex, 2nd ed. London, UK.

Descimon, H., 1977. Biogéographie, mimétisme et spéciation dans le genreAgrias Doubleday (Lep. Nymphalidae Charaxinae). Publ. Lab. Zool. de l'Ecole. Norm Sup 9, 307-344.

De-Silva, D.L., Elias, M., Willmott, K., Mallet, J., Day, J.J., 2016. Diversification of clearwing butterflies with the rise of the Andes. J Biogeogr 43, 44-58. https://doi.org/10.1111/jbi.12611

De-Silva, D.L., Mota, L.L., Chazot, N., Mallarino, R., Silva-Brandao, K.L., Pinerez, L.M.G., Freitas, A.V.L., Lamas, G., Joron, M., Mallet, J., Giraldo, C.E., Uribe, S., Sarkinen, T., Knapp, S., Jiggins, C.D., Willmott, K.R., Elias, M., 2017. North Andean origin and diversification of the largest ithomiine butterfly genus. Sci Rep-Uk 7. https://doi.org/10.1038/srep45966

Eastman, J.M., Alfaro, M.E., Joyce, P., Hipp, A.L., Harmon, L.J., 2011. A Novel Comparative Method for Identifying Shifts in the Rate of Character Evolution on Trees. Evolution 65, 3578-3589. https://doi.org/10.1111/j.1558-5646.2011.01401.x

Espeland, M., Breinholt, J., Willmott, K.R., Warren, A.D., Vila, R., Toussaint, E.F.A., Maunsell, S.C., Aduse-Poku, K., Talavera, G., Eastwood, R., Jarzyna, M.A., Guralnick, R., Lohman, D.J., Pierce, N.E., Kawahara, A.Y., 2018. A Comprehensive and Dated Phylogenomic Analysis of Butterflies. Current Biology 28, 770-778.e5. https://doi.org/10.1016/j.cub.2018.01.061

Fan, Y., Wu, R., Chen, M.H., Kuo, L., Lewis, P.O., 2011. Choosing among Partition Models in Bayesian Phylogenetics. Mol Biol Evol 28, 523-532. https://doi.org/10.1093/molbev/msq224

Felsenstein, J., 2004. Inferring Phylogenies. Sinauer, Sunderland, MA.

Finkbeiner, S.D., Briscoe, A.D., Reed, R.D., 2014. Warning signals are seductive: Relative contributions of color and pattern to predator avoidance and mate attraction in Heliconius butterflies. Evolution 68, 3410-3420. https://doi.org/10.1111/evo.12524

FitzJohn, R.G., 2010. Quantitative traits and diversification. Syst. Biol. 59, 619-633. https://doi.org/10.1093/sysbio/syq053

Fordyce, J.A., Nice, C.C., Forister, M.L., Shapiro, A.M., 2002. The significance of wing pattern diversity in the Lycaenidae: mate discrimination by two recently diverged species. J Evolution Biol 15, 871-879. https://doi.org/10.1046/j.1420-9101.2002.00432.x

Forest, F., 2009. Calibrating the Tree of Life: fossils, molecules and evolutionary timescales. Ann Bot-London 104, 789-794. https://doi.org/10.1093/aob/mcp192

Garzione, C.N., Hoke, G.D., Libarkin, J.C., Withers, S., MacFadden, B., Eiler, J., Ghosh, P., Mulch, A., 2008. Rise of the Andes. Science 320, 1304-1307. https://doi.org/10.1126/science.1148615

Harmon, L.J., Weir, J.T., Brock, C.D., Glor, R.E., Challenger, W., 2008. GEIGER: investigating evolutionary radiations. Bioinformatics 24, 129-131. https://doi.org/10.1093/bioinformatics/btm538

Harvey, M.G., Rabosky, D.L., 2018. Continuous traits and speciation rates: Alternatives to state-dependent diversification models. Methods in Ecology and Evolution 9, 984-993. https://doi.org/10.1111/2041210X.12949

Hoorn, C., Wesselingh, F.P., ter Steege, H., Bermudez, M.A., Mora, A., Sevink, J., Sanmartin, I., Sanchez-Meseguer, A., Anderson, C.L., Figueiredo, J.P., Jaramillo, C., Riff, D., Negri, F.R., Hooghiemstra, H., Lundberg, J., Stadler, T., Sarkinen, T., Antonelli, A., 2010. Amazonia Through Time: Andean Uplift, Climate Change, Landscape Evolution, and Biodiversity. Science 330, 927-931. https://doi.org/10.1126/science.1194585 
Jenkins, D.W., 1987. Neotropical Nymphalidae VI. Revision of Asterope (=Callithea Auct.). Bulletin of the Allyn Museum 1-66.

Jiggins, C., Naisbit, R., Coe, R., Mallet, J., 2001. Reproductive isolation caused by color pattern mimicry. Nature.

Jiggins, C.D., 2008. Ecological Speciation in Mimetic Butterflies. BioScience 58, 541-548. https://doi.org/10.1641/B580610

Jiggins, C.D., Mallarino, R., Willmott, K.R., Bermingham, E., 2006. The phylogenetic pattern of speciation and wing pattern change in neotropical Ithomia butterflies (Lepidoptera: nymphalidae). Evolution 60, 145466.

Josse, C., 2003. Ecological systems of Latin America and the Caribbean: a working classification of terrestrial systems. NatureServe.

Kemp, D.J., 2007. Female butterflies prefer males bearing bright iridescent ornamentation. Proceedings of the Royal Society B: Biological Sciences 274, 1043-1047. https://doi.org/10.1098/rspb.2006.0043

Kürschner, W.M., Kvaček, Z., Dilcher, D.L., 2008. The impact of Miocene atmospheric carbon dioxide fluctuations on climate and the evolution of terrestrial ecosystems. PNAS 105, 449-453. https://doi.org/10.1073/pnas.0708588105

Lagomarsino, L.P., Condamine, F.L., Antonelli, A., Mulch, A., Davis, C.C., 2016. The abiotic and biotic drivers of rapid diversification in Andean bellflowers (Campanulaceae). New Phytologist 210, 1430-1442. https://doi.org/10.1111/nph.13920

Lamas, G., 2004. Checklist: Part 4A. Hesperioidea - Papilionoidea, in: Atlas of Neotropical Lepidoptera. Associa-tion for Tropical Lepidoptera and Scientific Publishers, Gainesville, FL, p. 439.

Lanfear, R., Calcott, B., Ho, S.Y.W., Guindon, S., 2012. PartitionFinder: Combined Selection of Partitioning Schemes and Substitution Models for Phylogenetic Analyses. Mol Biol Evol 29, 1695-1701. https://doi.org/10.1093/molbev/mss020

Losos, J.B., Warheit, K.I., Schoener, T.W., 1997. Adaptive differentiation following experimental island colonization in Anolis lizards. Nature 387, 70-73. https://doi.org/10.1038/387070a0

Louca, S., Pennell, M.W., 2020. Extant timetrees are consistent with a myriad of diversification histories. Nature 580, 502-505. https://doi.org/10.1038/s41586-020-2176-1

Magallon, S., Sanderson, M.J., 2001. Absolute diversification rates in angiosperm clades. Evolution 55, 1762-1780. https://doi.org/10.1111/j.0014-3820.2001.tb00826.x

Mallet, J., Gilbert, L.E., 1995. Why are there so many mimicry rings? Correlations between habitat, behaviour and mimicry in Heliconiusbutterflies. Biological Journal of the Linnean Society 55, 159-180. https://doi.org/10.1111/j.1095-8312.1995.tb01057.x

Matzke, N.J., 2018. BioGeoBEARS: BioGeography with Bayesian (and likelihood) Evolutionary Analysis with R Scripts. GitHub. https://doi.org/10.5281/zenodo.1478250

Matzke, N.J., 2014. Model selection in historical biogeography reveals that founder-event speciation is a crucial process in island clades. Syst Biol 64, 167-167. https://doi.org/10.1093/sysbio/syu091

Mavarez, J., Salazar, C.A., Bermingham, E., Salcedo, C., Jiggins, C.D., Linares, M., 2006. Speciation by hybridization in Heliconiusbutterflies. Nature 441, 868-71. https://doi.org/10.1038/nature04738

Mayhew, P.J., 2007. Why are there so many insect species? Perspectives from fossils and phylogenies. Biol Rev Camb Philos Soc 82, 425-54. https://doi.org/10.1111/j.1469-185X.2007.00018.x 
Montes, C., Cardona, A., Jaramillo, C., Pardo, A., Silva, J.C., Valencia, V., Ayala, C., Perez-Angel, L.C., Rodriguez-Parra, L.A., Ramirez, V., Nino, H., 2015. Middle Miocene closure of the Central American Seaway. Science 348, 226-229. https://doi.org/10.1126/science.aaa2815

Morlon, H., 2014. Phylogenetic approaches for studying diversification. Ecology Letters 17, 508-525. https://doi.org/10.1111/ele.12251

Morlon, H., Lewitus, E., Condamine, F.L., Manceau, M., Clavel, J., Drury, J., 2016. RPANDA: an R package for macroevolutionary analyses on phylogenetic trees. Methods in Ecology and Evolution 7, 589597. https://doi.org/10.1111/2041-210X.12526

Morlon, H., Parsons, T.L., Plotkin, J.B., 2011. Reconciling molecular phylogenies with the fossil record. PNAS 108, 16327-16332. https://doi.org/10.1073/pnas.1102543108

Mullen, S.P., Savage, W.K., Wahlberg, N., Willmott, K.R., 2011. Rapid diversification and not clade age explains high diversity in neotropicalAdelpha butterflies. P Roy Soc B-Biol Sci 278, 1777-1785. https://doi.org/10.1098/rspb.2010.2140

Nadeau, N.J., Pardo-Diaz, C., Whibley, A., Supple, M.A., Saenko, S.V., Wallbank, R.W.R., Wu, G.C., Maroja, L., Ferguson, L., Hanly, J.J., Hines, H., Salazar, C., Merrill, R.M., Dowling, A.J., ffrench-Constant, R.H., Llaurens, V., Joron, M., McMillan, W.O., Jiggins, C.D., 2016. The gene cortex controls mimicry and crypsis in butterflies and moths. Nature 534, 106-110. https://doi.org/10.1038/nature17961

Neild, A.F.E., 1996. The Butterflies of Venezuela. Part 1: Nymphalidae I (Limenitidinae, Apaturinae, Charaxinae). A comprehensive guide to the identi cation of adult Nymphalidae, Papilionidae, and Pieridae. Meridian Publications, Greenwich.

Nicholson, D.B., Ross, A.J., Mayhew, P.J., 2014. Fossil evidence for key innovations in the evolution of insect diversity. Proc Biol Sci 281. https://doi.org/10.1098/rspb.2014.1823

Nijhout, F., 1991. The Development and Evolution of the Butterfly Wing Patterns. Smithsonian Institution Press.

Obara, Y., Majerus, M.E.N., 2000. Initial Mate Recognition in the British Cabbage Butterfly, Pieris rapae rapae. Zoological Science 17, 725-730. https://doi.org/10.2108/zsj.17.725

Oliver, J.C., Tong, X.-L., Gall, L.F., Piel, W.H., Monteiro, A., 2012. A Single Origin for Nymphalid Butterfly Eyespots Followed by Widespread Loss of Associated Gene Expression. PLOS Genetics 8, e1002893. https://doi.org/10.1371/journal.pgen.1002893

Ortiz-Acevedo, E., Bonfantti, D., Casagrande, M., Mielke, O.H.H., Espeland, M., Willmott, K.R., 2017. Using Molecules and Morphology to Unravel the Systematics of Neotropical Preponine Butterflies (Lepidoptera: Charaxinae: Preponini). Insect Syst Divers 1, 48-56. https://doi.org/10.1093/isd/ixx002

Ortiz-Acevedo, E., Willmott, K.R., 2013. Molecular systematics of the butterfly tribe Preponini (Nymphalidae: Charaxinae). Systematic Entomology 38, 440-449. https://doi.org/10.1111/syen.12008

Paradis, E., Claude, J., Strimmer, K., 2004. APE: Analyses of Phylogenetics and Evolution in R language. Bioinformatics 20, 289-290. https://doi.org/10.1093/bioinformatics/btg412

Peña, C., Espeland, M., 2015. Diversity Dynamics in Nymphalidae Butterflies: Effect of Phylogenetic Uncertainty on Diversification Rate Shift Estimates. Plos One 10. https://doi.org/10.1371/journal.pone.0120928

Peña, C., Wahlberg, N., 2008. Prehistorical climate change increased diversification of a group of butterflies. Biol. Lett. 4, 274-278. https://doi.org/10.1098/rsbl.2008.0062

Pinto-Sanchez, N.R., Ibanez, R., Madrinan, S., Sanjur, O.I., Bermingham, E., Crawford, A.J., 2012. The Great American Biotic Interchange in frogs: multiple and early colonization of Central America by 
the South American genus Pristimantis (Anura: Craugastoridae). Mol Phylogenet Evol 62, 954-72. https://doi.org/10.1016/j.ympev.2011.11.022

Pound, M.J., Haywood, A.M., Salzmann, U., Riding, J.B., Lunt, D.J., Hunter, S.J., 2011. A Tortonian (Late Miocene, 11.61-7.25Ma) global vegetation reconstruction. Palaeogeography, Palaeoclimatology, Palaeoecology 300, 29-45. https://doi.org/10.1016/j.palaeo.2010.11.029

Pybus, O.G., Harvey, P.H., 2000. Testing Macro-Evolutionary Models Using Incomplete Molecular Phylogenies. Proceedings: Biological Sciences 267, 2267-2272.

Rabosky, D.L., 2014. Automatic Detection of Key Innovations, Rate Shifts, and Diversity-Dependence on Phylogenetic Trees. PLoS One 9. https://doi.org/10.1371/journal.pone.0089543

Raftery, A.E., Satagopan, J.M., Newton, M.A., Krivitsky, P.N., 2007. Estimating the integrated likelihood via posterior simulation using the harmonic mean identity, in: Bernardo, J.M., Bayarri, M.J., Berger, J.O., Dawid, A.P., Heckerman, D., Smith, A.F.M., West, M. (Eds.), Bayesian Statistics. Oxford University Press, London, UK, pp. 1-45.

Rahbek, C., Borregaard, M.K., Antonelli, A., Colwell, R.K., Holt, B.G., Nogues-Bravo, D., Rasmussen, C.M.Ø., Richardson, K., Rosing, M.T., Whittaker, R.J., Fjeldså, J., 2019. Building mountain biodiversity: Geological and evolutionary processes. Science 365, 1114-1119. https://doi.org/10.1126/science.aax0151

Rambaut, A., Suchard, M.A., Xie, D., Drummond, A., 2014. Tracer v1.6.

Rasband, W.S., 1997. ImageJ. National Institute of Health, Bethesda, Maryland, USA.

Ree, R.H., Sanmartín, I., 2018. Conceptual and statistical problems with the DEC+J model of founderevent speciation and its comparison with DEC via model selection. Journal of Biogeography 45, 741-749. https://doi.org/10.1111/jbi.13173

Ree, R.H., Smith, S.A., 2008. Maximum Likelihood Inference of Geographic Range Evolution by Dispersal, Local Extinction, and Cladogenesis. Systematic Biology 57, 4-14.

Reed, R.D., Papa, R., Martin, A., Hines, H.M., Counterman, B.A., Pardo-Diaz, C., Jiggins, C.D., Chamberlain, N.L., Kronforst, M.R., Chen, R., Halder, G., Nijhout, H.F., McMillan, W.O., 2011. optix drives the repeated convergent evolution of butterfly wing pattern mimicry. Science 333, 1137-1141. https://doi.org/10.1126/science.1208227

Ronquist, F., 1997. Dispersal-vicariance analysis: A new approach to the quantification of historical biogeography. Syst Biol 46, 195-203. https://doi.org/10.2307/2413643

Ronquist, F., Sanmartin, I., 2011. Phylogenetic Methods in Biogeography. Annu Rev Ecol Evol S 42, 441-464. https://doi.org/10.1146/annurev-ecolsys-102209-144710

Sahoo, R.K., Warren, A.D., Collins, S.C., Kodandaramaiah, U., 2017. Hostplant change and paleoclimatic events explain diversification shifts in skipper butterflies (Family: Hesperiidae). Bmc Evol Biol 17. https://doi.org/10.1186/s12862-017-1016-x

Schluter, D., 2000. The Ecology of Adaptive Radiation. Oxford University Press, New York.

Schneider, C., Rasband, W., Eliceiri, K., 2012. NIH Image to ImageJ: 25 years of image analysis.

Smith, B.T., McCormack, J.E., Cuervo, A.M., Hickerson, M.J., Aleixo, A., Cadena, C.D., PerezEman, J., Burney, C.W., Xie, X., Harvey, M.G., Faircloth, B.C., Glenn, T.C., Derryberry, E.P., Prejean, J., Fields, S., Brumfield, R.T., 2014. The drivers of tropical speciation. Nature 515, 406-9. https://doi.org/10.1038/nature13687

Strömberg, C.A.E., Dunn, R.E., Madden, R.H., Kohn, M.J., Carlini, A.A., 2013. Decoupling the spread of grasslands from the evolution of grazer-type herbivores in South America. Nat Commun 4, 1478. https://doi.org/10.1038/ncomms2508 
Taper, M.L., Ponciano, J.M., 2016. Evidential statistics as a statistical modern synthesis to support 21st century science. Popul Ecol 58, 9-29. https://doi.org/10.1007/s10144-015-0533-y

Toussaint, E.F.A., Dias, F.M.S., Mielke, O.H.H., Casagrande, M.M., Sañudo-Restrepo, C.P., Lam, A., Morinière, J., Balke, M., Vila, R., 2019. Flight over the Proto-Caribbean seaway: Phylogeny and macroevolution of Neotropical Anaeini leafwing butterflies. Molecular Phylogenetics and Evolution 137, 86-103. https://doi.org/10.1016/j.ympev.2019.04.020

Turrent Carriles, A., García Días, J. de J., 2019. Descripcion de una nueva especie de Prepona Boisduval, 1836 (Lepidoptera: Nymphalidae) de la Sierra Madre del Sur. Revista de la Sociedad Mexicana de Lepidopterología VII.

Wahlberg, N., Leneveu, J., Kodandaramaiah, U., Peña, C., Nylin, S., Freitas, A.V.L., Brower, A.V.Z., 2009. Nymphalid butterflies diversify following near demise at the Cretaceous/Tertiary boundary. Proceedings of the Royal Society B: Biological Sciences 276, 4295-4302. https://doi.org/10.1098/rspb.2009.1303

Wallace, A.R., 1889. Darwinism: an exposition of the theory of natural selection with some of its applications. Macmillan and Company, London, UK.

Wallace, A.R., 1877. The colours of animals and plants. The American Naturalist 11, 713-728.

Weir, J.T., Bermingham, E., Schluter, D., 2009. The Great American Biotic Interchange in birds. Proc Natl Acad Sci U S A 106, 21737-42. https://doi.org/10.1073/pnas.0903811106

Table 1. Model specifications for the RPANDA diversification rate analyses.

\begin{tabular}{|c|c|c|c|c|c|c|c|c|}
\hline & & & Lambda & Lambda & $\mathrm{Mu}$ & $\mathrm{Mu}$ & & \\
\hline & Lambda & $\mathrm{Mu}$ & Intercept & Coefficient & Intercept & Coefficient & Loglik & AIC \\
\hline L tMLE NAOAELS & Constant & Zero & 0.12 & & 0 & & -90.9 & 183.8 \\
\hline & Exponential & Zero & 0.15 & -0.03 & 0 & & -89.9 & 183.8 \\
\hline & Constant & Constant & 0.13 & & -0.04 & & -90.7 & 185.4 \\
\hline & Exponential & Constant & 0.15 & -0.03 & $>0.0001$ & & -89.9 & 185.8 \\
\hline & Exponential & Exponential & 0.15 & -0.03 & $>0.0001$ & 0.03 & -89.9 & 187.8 \\
\hline & Constant & Exponential & 0.14 & & 0.01 & 0.11 & -89.6 & 185.2 \\
\hline \multicolumn{9}{|l|}{ Andes Models } \\
\hline & Exponential & Zero & 0.02 & 0.49 & 0 & & -89.7 & 183.4 \\
\hline & Exponential & Constant & 1.14 & -0.43 & 0.18 & & -94.4 & 194.8 \\
\hline & Constant & Exponential & 0.14 & & 0.72 & -0.93 & -89.7 & 185.4 \\
\hline \multicolumn{9}{|l|}{ Panama Isthmus Models } \\
\hline & Exponential & Zero & 0.06 & 0.8 & 0 & & -90.2 & 184.4 \\
\hline & Exponential & Constant & 0.04 & 1.23 & $>0.0001$ & & -90.7 & 187.4 \\
\hline & Constant & Exponential & 0.11 & & $>0.0001$ & 0.7 & -90.9 & 187.8 \\
\hline
\end{tabular}

Table 2. Biogeographic hypotheses tested in the study. na: Not applicable

\begin{tabular}{ll}
\hline Code & Hypotheses \\
Ho1 & Null \\
& $\begin{array}{l}\text { There is no restriction to dispersal. } \\
\text { Ho2 }\end{array} \begin{array}{l}\text { Restriction to dispersal by distance } \\
\text { Geographical events do not have any influence on the ancestral range reconstruction. Dispersal is only restricted by }\end{array}$ \\
Ho3 & Restriction to dispersal - Panama
\end{tabular}


The gradual closing of the Panama Isthmus is the only geographical event that influenced Preponini dispersal.

Ho4 Restriction to dispersal - Andes

The gradual uplift of the Andes mountain range is the only geographical event that influenced Preponini dispersal.

Ho5 Restriction to dispersal-Distance + Andes

Preponini dispersal was influenced by a combination of geographic distance and the uplift of the Andes mountain r

Ho6 Restriction to dispersal - Distance + Panama

Preponini dispersal was influenced by a combination of geographic distance and the closing of the Panama Isthmus.

Ho7 Restriction to dispersal - Panama + Andes

Preponini dispersal was influenced by a combination of both the closing of the Panama Isthmus and the uplift of th

Ho8 Restriction to dispersal - Distance + Andes + Panama

Preponini dispersal was influenced by a combination of geographic distance, the closing of the Panama Isthmus and

Table 3. Evolutionary rates for the mean and mode color of the different areas of the wing measured. $\alpha$ is defined as the estimated value of the character at the root and ?2 as the evolutionary rate (or variance).

\begin{tabular}{|c|c|c|c|c|c|c|c|c|c|c|c|}
\hline Mean & Mean & Mean & Mean & Mean & Mean & Mean & Mode & Mode & Mode & Mode & Mode \\
\hline $\begin{array}{l}\text { Measurement } \\
\text { Wing }\end{array}$ & $\alpha$ & Jumps & $? 2$ & LnL & $\mathrm{AIC}$ & Model & $\begin{array}{l}\text { Measurement } \\
\text { Wing }\end{array}$ & $\alpha$ & Jumps & $? 2$ & LnL \\
\hline Total & 102.36 & & 18.69 & -112.57 & 227.25 & $\mathrm{BM}$ & Total & 82.96 & & 53.02 & -129 . \\
\hline Red & 125.36 & & 60.19 & -131.53 & 264.74 & $\mathrm{BM}$ & Red & 128.85 & & 186.52 & -157. \\
\hline Green & 98.41 & & 23.74 & -116.29 & 234.51 & $\mathrm{BM}$ & Green & 73.66 & & 20.68 & -118. \\
\hline Blue & 82.86 & & 39.18 & -126.65 & 255.07 & $\mathrm{BM}$ & Blue & 83.12 & & 232.9 & -168 . \\
\hline Cell 1 & & & & & & & Cell 1 & & & & \\
\hline Total & 77.02 & & 50.06 & -127.7 & 257.11 & BM & Total & 64.5 & 1.37 & 35.71 & -126 . \\
\hline Red & 106.8 & 2.68 & 50.97 & -139.71 & 295.6 & jump-BM & Red & 92.43 & 2.19 & 49.92 & -14 \\
\hline Green & 68.04 & & 35.93 & -123.84 & 249.34 & $\mathrm{BM}$ & Green & 55.6 & & 45.93 & $-12 \xi$ \\
\hline Blue & 49.09 & & 48.11 & -132.46 & 266.6 & $\mathrm{BM}$ & Blue & 40.23 & & 48.33 & -13 \\
\hline Cell 2 & & & & & & & Cell 2 & & & & \\
\hline Total & 90.91 & & 39.44 & -126.52 & 254.52 & $\mathrm{BM}$ & Total & 86.93 & & 41.99 & -130 \\
\hline Red & 125.7 & & 49.74 & -129.17 & 260.12 & $\mathrm{BM}$ & Red & 137.32 & & 137.37 & -15 \\
\hline Green & 83.83 & & 42.62 & -129.46 & 260.37 & $\mathrm{BM}$ & Green & 76.6 & & 41.53 & -129 . \\
\hline Blue & 61.4 & 2.27 & 27.49 & -124.13 & 267.07 & jump-BM & Blue & 47.66 & 3.85 & 17.55 & -13 \\
\hline Cell 3 & & & & & & & Cell 3 & & & & \\
\hline Total & 113.36 & & 23.47 & -116.1 & 234.42 & $\mathrm{BM}$ & Total & 99.23 & & 69.91 & -13 \\
\hline Red & 123.61 & & 105.08 & -142.11 & 286.67 & $\mathrm{BM}$ & Red & 128.92 & & 181.99 & -15 \\
\hline Green & 112.19 & & 39.95 & -124.07 & 249.67 & $\mathrm{BM}$ & Green & 85.41 & & 54.28 & -13 \\
\hline Blue & 102.75 & & 70.17 & -135.95 & 273.68 & BM & Blue & 107.52 & & 182.32 & -16 \\
\hline
\end{tabular}

Table 4. Trait-dependent diversification analysis for the mean and mode color traits.

\begin{tabular}{llllll}
\hline Mean & Mean & Mean & Mode & Mode & Mode \\
\hline $\begin{array}{l}\text { Measurement } \\
\text { Wing }\end{array}$ & rho & p-value & $\begin{array}{l}\text { Measurement } \\
\text { Wing }\end{array}$ & rho & p-value \\
Total & 0.15 & 0.81 & Total & 0.15 & 0.81 \\
Red & 0.25 & 0.67 & Red & 0.25 & 0.67 \\
Green & -0.41 & 0.42 & Green & -0.41 & 0.43 \\
Blue & 0.25 & 0.67 & Blue & 0.25 & 0.68
\end{tabular}




\begin{tabular}{lcclcc}
\hline Mean & Mean & Mean & Mode & Mode & Mode \\
\hline Cell 1 & & & Cell 1 & & \\
Total & 0.43 & 0.39 & Total & 0.43 & 0.39 \\
Red & 0.33 & 0.56 & Red & 0.33 & 0.56 \\
Green & 0.00 & 1.00 & Green & 0.00 & 1.00 \\
Blue & 0.54 & 0.18 & Blue & 0.54 & 0.18 \\
Cell 2 & & & Cell 2 & & \\
Total & 0.04 & 0.95 & Total & 0.04 & 0.95 \\
Red & -0.11 & 0.87 & Red & -0.11 & 0.87 \\
Green & -0.24 & 0.69 & Green & -0.24 & 0.70 \\
Blue & 0.33 & 0.55 & Blue & 0.33 & 0.56 \\
Cell 3 & & & Cell 3 & & \\
Total & 0.17 & 0.79 & Total & 0.17 & 0.78 \\
Red & 0.34 & 0.54 & Red & 0.34 & 0.55 \\
Green & -0.39 & 0.45 & Green & -0.39 & 0.45 \\
Blue & 0.09 & 0.89 & Blue & 0.09 & 0.89 \\
\hline & & & & &
\end{tabular}

Table 5. BioGeoBEARS results for the models and hypotheses tested in the study. Bold text references the best model identified for the data. d: Dispersal, e: Extinction, x: Distance, na: Not applicable

\begin{tabular}{lllllllll}
\hline Model & Hypothesis & LnL & \# Parameters & $\mathrm{d}$ & $\mathrm{e}$ & $\mathrm{x}$ & AIC & $\Delta$ AIC \\
\hline DEC & Ho1 & -147.54 & 2 & 0.06 & 0.05 & na & 299.09 & 15.13 \\
DEC & Ho2 & -284.93 & 3 & 0.20 & 0.42 & 1 & 575.87 & 291.91 \\
DEC & Ho3 & -148.30 & 2 & 0.07 & 0.03 & na & 300.59 & 16.63 \\
DEC & Ho4 & -144.13 & 2 & 0.16 & 0.10 & na & 292.27 & 8.31 \\
DEC & Ho5 & -217.62 & 3 & 0.20 & 0.42 & 1 & 441.23 & 157.27 \\
DEC & Ho6 & -263.13 & 3 & 0.20 & 0.42 & 1 & 532.26 & 248.30 \\
DEC & Ho7 & -139.98 & 2 & 0.22 & 0.10 & na & 283.96 & 0.00 \\
DEC & Ho8 & -164.86 & 3 & 0.20 & 0.42 & 1 & 335.73 & 51.77 \\
DIVA & Ho1 & -148.10 & 2 & 0.07 & 0.05 & na & 300.21 & 16.25 \\
DIVA & Ho2 & -285.73 & 3 & 0.20 & 0.42 & 1 & 577.46 & 293.50 \\
DIVA & Ho3 & -148.96 & 2 & 0.08 & 0.03 & na & 301.93 & 17.97 \\
DIVA & Ho4 & -145.09 & 2 & 0.14 & 0.06 & na & 294.17 & 10.21 \\
DIVA & Ho5 & -216.76 & 3 & 0.20 & 0.42 & 1 & 439.53 & 155.57 \\
DIVA & Ho6 & -263.44 & 3 & 0.20 & 0.42 & 1 & 532.89 & 248.93 \\
DIVA & Ho7 & -143.29 & 2 & 0.18 & 0.05 & na & 290.57 & 6.61 \\
DIVA & Ho8 & -161.44 & 3 & 0.20 & 0.42 & 1 & 328.88 & 44.92 \\
\hline
\end{tabular}

c

Figure Legends

Figure 1. Example Preponini species. Butterflies shown (from left to right across each row): Archaeoprepona licomedes, A. demophon, A. demophoon, A. amphimachus, A. meander, A. camilla, A. chalciope, A. priene, Mesoprepona pheridamas, Prepona dexamenus, P. laertes, P. werneri, P. gnorima, P. deiphile, P. praeneste, P. narcissus, P. aedon, P. hewitsonius, P. claudina, P. amydon. Photos by P. S. Padrón and A. Warren.

Figure 2. Ancestral reconstruction of the mode RGB red channel for the Cell 1 and lineage-through-time plot (solid blue line). Blue dotted line denotes expectation of lineage accumulation under a pure birth process. Red, blue, and gray triangles highlight branches where a jump in color was identified for the blue, red and 
total channels in Cells 1, 2, and 3 (see text for details). Vertical color bars denote the red and blue Preponini clades. Abbreviations follow: PL: Pliocene, P: Pleistocene. Butterflies shown (from top to bottom): Prepona claudina, P. laertes, Mesoprepona pheridamas, and Archaeoprepona licomedes. Photos by P. S. Padrón.

Figure 3.Biogeographical range estimates for the tribe Preponini based on the DEC model. Dotted gray lines delimit the time slices used in the stratified analysis. Upward black triangles denote periods of increased Andean uplift (Hoorn et al. 2010), downward black triangles denote periods of increased biological migration between Central and South America, and downward white triangle denotes initial faunal exchange between Central and South America $41 \mathrm{Ma}$ (Bacon et al. 2015). Roman numerals in nodes refer to the main text. Abbreviations follow: PL: Pliocene, P: Pleistocene. Butterflies shown (from top to bottom):Archaeoprepona meander, A. chalciope, A. licomedes, A. priene, Mesoprepona pheridamas, Prepona laertes, P. werneri, $P$. praeneste, P. narcissus, P. claudina. Photos by P. S. Padrón and EOA.

Data accessibility statement

Most DNA data has been deposited in GenBank. The remaining data will be archived upon acceptance of the manuscript.

Competing interest statement

We declare no conflict of interests.

Autor contributions

EOA and KRW conceived and designed the study. EOA gathered the data. EOA and JPG performed analyses and drafted the manuscript. ME, EFAT and KRW assisted with the analyses and manuscript writing. All authors have approved the final version of the manuscript.

Acknowledgements

We are deeply grateful to everyone that was involved in the field and who donated material to be included in this study. We thank P. S. Padrón and A. Warren for providing some photographs. We thank the collection managers in the institutions we visited for allowing us to access the specimens. We thank Dr. Lei Xiao for her invaluable help in the molecular laboratory. We are also thankful to our funding sources: Sigma Xi (Grants-in-Aid of Research G20100315153261), the Center for Systematic Entomology, the Council of the Linnean Society and the Systematics Association for the Systematics Research Fund, the William C. and Bertha M. Cornett Fellowship, the College of Agricultural and Life Sciences, the Florida Foundation, the AMNH collections study grant, and COLCIENCIAS Doctorados en el exterior 2016 awarded to EOA. 

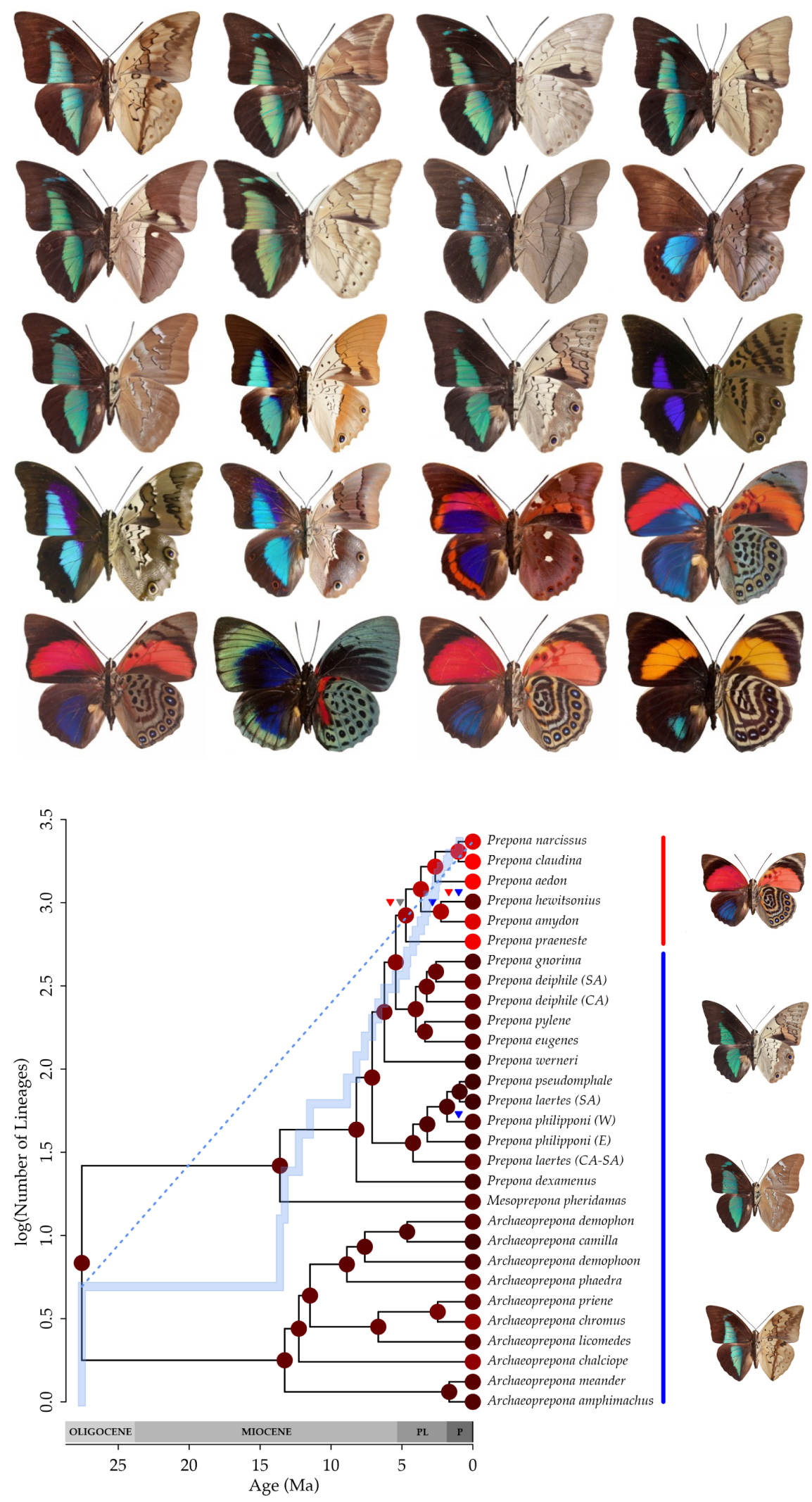

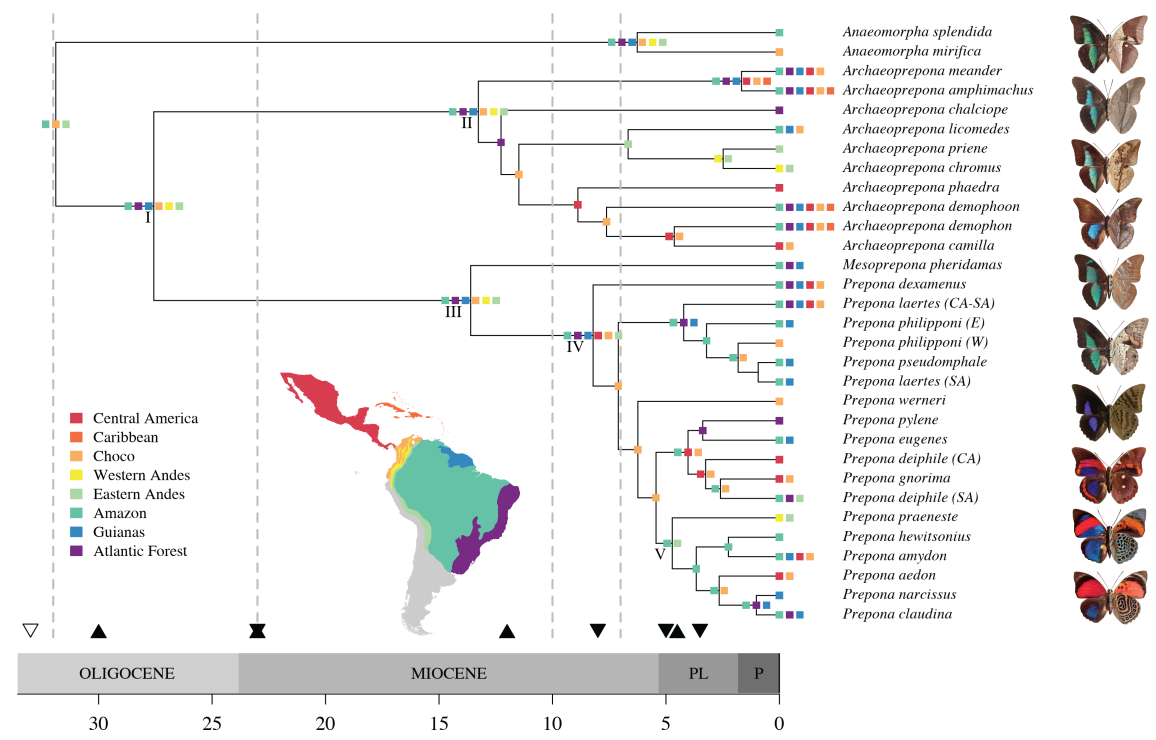